\title{
Student-Designed Projects in Computational Fluid Dynamics: Challenges and Results
}

\author{
Daniel N. Pope \\ University of Minnesota Duluth
}

\begin{abstract}
The use of final projects that are selected and designed by students in a senior level, undergraduate Computational Fluid Dynamics (CFD) course is discussed. Analysis of products and systems that include heat transfer and fluid flow using CFD software is becoming a required part of the design process. Prospective employers are looking for undergraduate students that have some experience performing CFD analyses. However, the techniques used in CFD are often problem dependent and can involve mathematics that is beyond the undergraduate level. In addition, CFD analysis is still somewhat of an art form where the adjusting of multiple solution "parameters" can change a useless model into a robust, physically realistic model. In order to provide undergraduate students with the necessary background, the basic theory for pressurebased solutions on regular, structured meshes is often presented with simple numerical examples to reinforce the lessons. The theory and the examples are limited in scope and they discuss only a fraction of the available CFD techniques. The course discussed here utilizes a final project to address these shortcomings. Each student designs their own problem at the beginning of the semester with guidance from the instructor. As a result, students generally take ownership of their projects, they learn material specific to their projects and beyond that taught in class, and they communicate that material to their classmates. Since each student's project is different, there is usually an increased demand on the instructor's time. This paper presents the structure of the CFD course, the problems designed by the students, the models they employed, the challenges faced by the instructor, and the lessons learned.
\end{abstract}

\section{Introduction}

The evolution of modern computers and simulation tools has had a profound effect on the engineering profession. Engineering problems that were once addressed by government researchers or industry research and design teams using custom computer codes can now be routinely solved using commercial codes on desktop computers. Companies routinely use these codes to solve a wide range of engineering problems. Academic courses covering different simulation techniques have been increasingly offered at the undergraduate level to address industry needs.

To reduce both the cost and development time, today's products and systems are now frequently designed and analyzed using computational simulation tools. Many tools, such as computeraided design (CAD) codes and finite element analysis (FEA) packages, are well-established in the mechanical engineering design process. Computational fluid dynamics (CFD) simulations 
have been increasingly incorporated in the design process during the past decade. As a result, ASME has recently published a standard governing the verification and validation of CFD results ${ }^{1}$.

The field of CFD addresses the modeling and prediction of fluid flow, heat and mass transfer, chemical reactions, and other flow phenomena via the numerical solution of governing mathematical equations. Courses that introduce CFD methods have been a part of graduate programs in mechanical engineering for decades. Many prospective employers are looking for undergraduate students that have some experience performing CFD analyses; however, CFD courses are not always available to undergraduate students ${ }^{2}$.

This paper discusses the undergraduate CFD course taught at the University of Minnesota Duluth (UMD). The structure of the course is described, and a summary and discussion of the studentdesigned projects is presented. Finally, the conclusion addresses the lessons learned and future plans for the course.

\section{Course Structure}

The CFD course taught at UMD is a senior level, advanced technical elective offered by the Department of Mechanical and Industrial Engineering. The course is taught during the spring semester of odd years (once every two years) and the author has taught the course four times (spring of 2005, 2007, 2009, and 2011). Prerequisites for the CFD course include the computer programming, CAD, Calculus (I-III), Differential Equations, Fluid Dynamics, Thermodynamics, and Heat and Mass Transfer courses. ANSYS Workbench 12.1 with the Meshing and Fluent modules is the commercial code that is used within the course. A newer textbook by Tu et al. ${ }^{3}$ was used in spring 2011; previous semesters utilized a book by Patankar ${ }^{4}$. The course is three credit hours and meets three hours per week; two hours per week are spent in lecture, and one hour per week is spent in the computer lab.

Lectures covered the following topics over the course of the semester: the CFD solution procedure, the governing equations for incompressible flow with heat transfer, the Reynolds Averaged Navier Stokes equations, the k- $\varepsilon$ turbulence model, the finite-difference method (FDM), the finite-volume method (FVM), numerical solution of algebraic equations, and CFD solution analysis. Computer lab sessions focused on familiarizing the students with the capabilities and use of the ANSYS software. Students were expected to perform various tutorials available on the ANSYS Customer Portal ${ }^{5}$ and at Cornell University's SimCafe website ${ }^{6}$ and present a summary of the techniques and tools that they learned about in each tutorial. They were also prompted to access materials appropriate to their individual project from the ANSYS Customer Portal ${ }^{5}$ and Resource Library ${ }^{7}$. Several lab sessions where used to review meshing including structured and unstructured meshes. Figure 1 shows examples used in the lab of an unstructured mesh (Fig. 1a) and a structured mesh (Fig. 1b) for axisymmetric flow over a cylinder. 
The coursework consists of weekly homework, two exams, and a final proposal. Students are assessed based on a weighted average of the coursework. Exams have an in-class and take-home portion. The in-class portion emphasizes concepts and theory and the take-home portion consists of using the software to solve a problem.

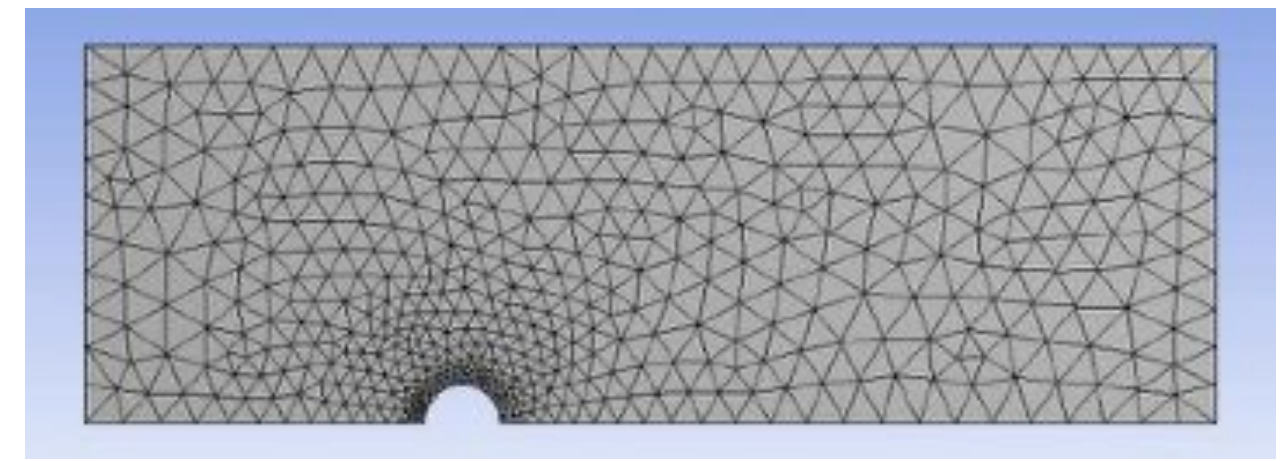

(a) Unstructured

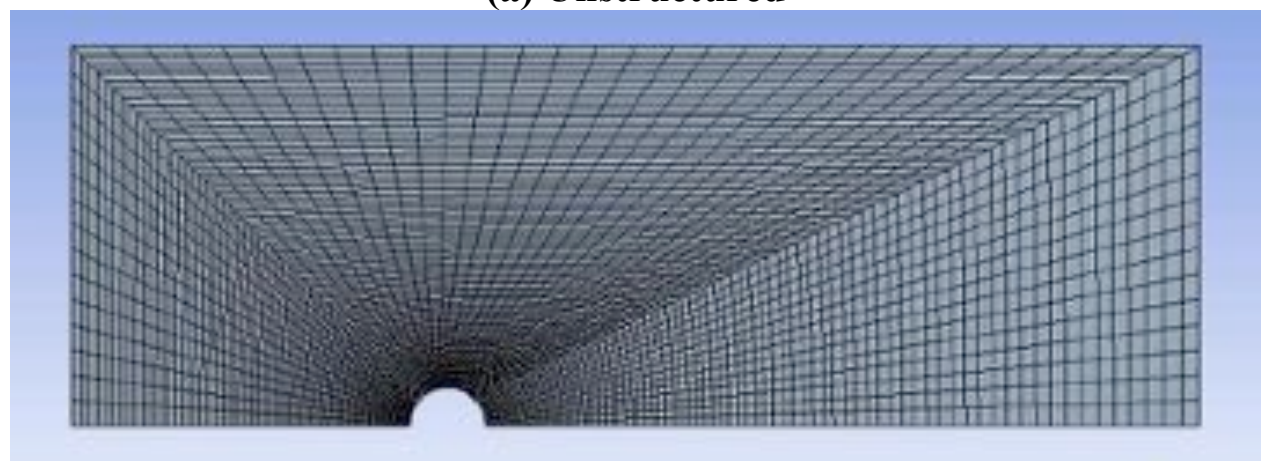

(b) Structured

Figure 1: Mesh examples for axisymmetric flow over a cylinder.

The final proposal is the culmination of the "project" for the course. Students submit a one to two page initial proposal at the end of the third week of class. At that point in the course, they have completed at least two tutorials and have a limited working knowledge of the capabilities of the software. The initial proposal states the problem that will be investigated, justifies the use of a numerical model (i.e. the problem has no analytical solution), identifies the modeling objectives, and defines a work plan with specific milestones and due dates. The instructor reviews the initial proposal, provides suggestions, and returns it to the student. This document provides the basis for the project work during the course of the semester. If the student does a good job on the initial proposal, the project generally proceeds smoothly and they have a good start on the introduction for the final proposal. The student submits a proposal update memo mid-semester. This memo discusses the tasks completed, any remaining tasks with due dates, and any changes to the scope of the project that have occurred. The project concludes with the submission of the final proposal at the end of the semester. The goal of the project is not to produce an exhaustive analysis of a given problem; the final proposal presents preliminary results and details the work remaining to complete the exhaustive analysis. The final proposal should not be longer than 10 pages and should contain the following sections: an executive 
summary, an introduction to define the problem and discuss any work that others have done to address the problem, a results section to discuss what the student has done and the methods used to obtain the results, and a conclusion that discusses the additional work needed to fully analyze the problem using CFD.

\section{Discussion of Projects}

Twenty one different projects encompassing a wide variety of fluid flow problems were submitted at the end of the Spring 2011 semester. Inspiration for the projects came from a variety of sources including other technical electives, the senior design course, hobbies, potential graduate school topics, formula SAE student design, and general interest. Twelve of the twenty one projects involved the use of model characteristics that were not discussed in the lecture or addressed in the lab. Some examples of these projects are discussed below.

Figure 2 shows the mesh and named surfaces (Fig. 2a) and one set of static pressure contour results (Fig. 2b) from a project that analyzed the flow through a single gas turbine stage. The flow is compressible, and the solution uses specialized techniques such as a moving mesh for the rotor, period boundary conditions at the upper and lower boundaries for the rotor and the stator, and a mixing plane boundary is located at the junction of the stator outlet and the rotor inlet.

Subsonic and supersonic flow over a delta wing was also investigated using CFD. Figure 3 shows the pressure distribution around the wing at zero angle of attack and a speed of Mach 2. Grid and domain size dependence checks were also presented as well as results for rounded and sharp leading edge geometries at varying speeds. The 3-D compressible flow results using two different turbulence models, the one equation Spalart-Allmaras model and the two equation k- $\omega$ SST model, were discussed.

Another student modeled the geometry effects on turbulence in a ramjet combustor. Figure 4 shows the pathlines obtained for one set of inlet conditions and geometry. The solution for the internal compressible flow was obtained using a density-based solver as opposed to the more commonly employed pressure-based solver. Results for various geometries at specified inlet conditions were compared to experimental results available in the literature.

The final project example is a transient model of the compressible flow in a preliminary design for the intake plenum on UMD's newest Formula SAE (FSAE) racecar. Figure 5 shows the velocity vectors in the inlet plenum at a specified time $(0.001 \mathrm{~s})$ during the intake stroke. The simulation was conducted with the one equation Spalart-Allmaras model for turbulence, and a user-defined function (UDF) was employed in Fluent to model the time-varying pressure boundary condition at the outlet of the plenum. A video of the flow in the plenum covering the entire intake, compression, expansion, exhaust sequence was created. 


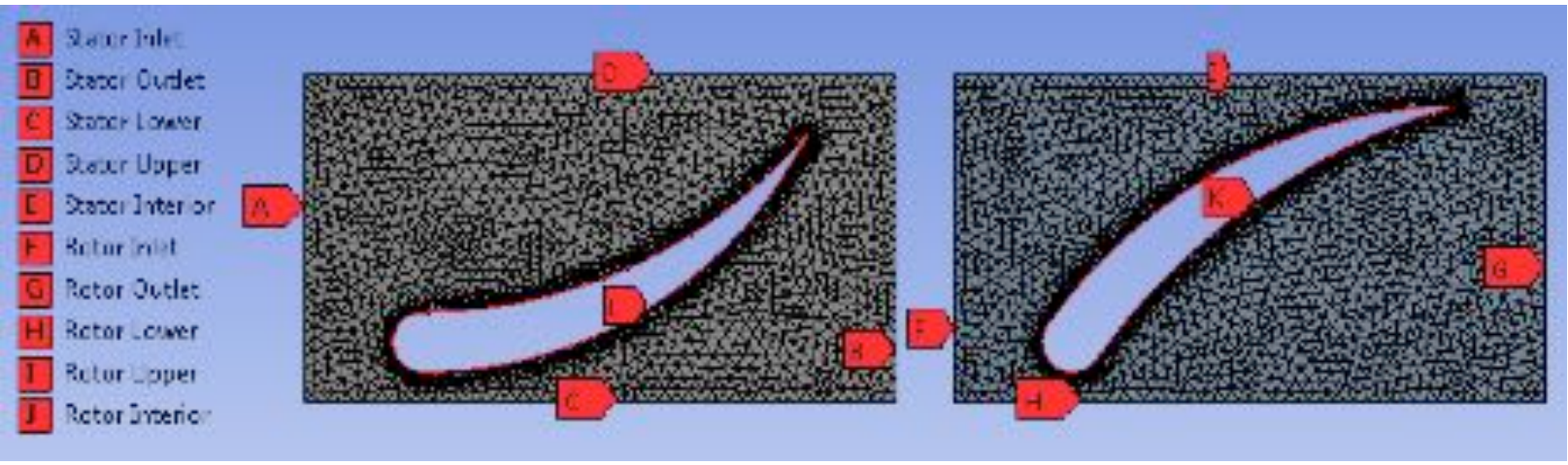

(a) Mesh and Named Surfaces

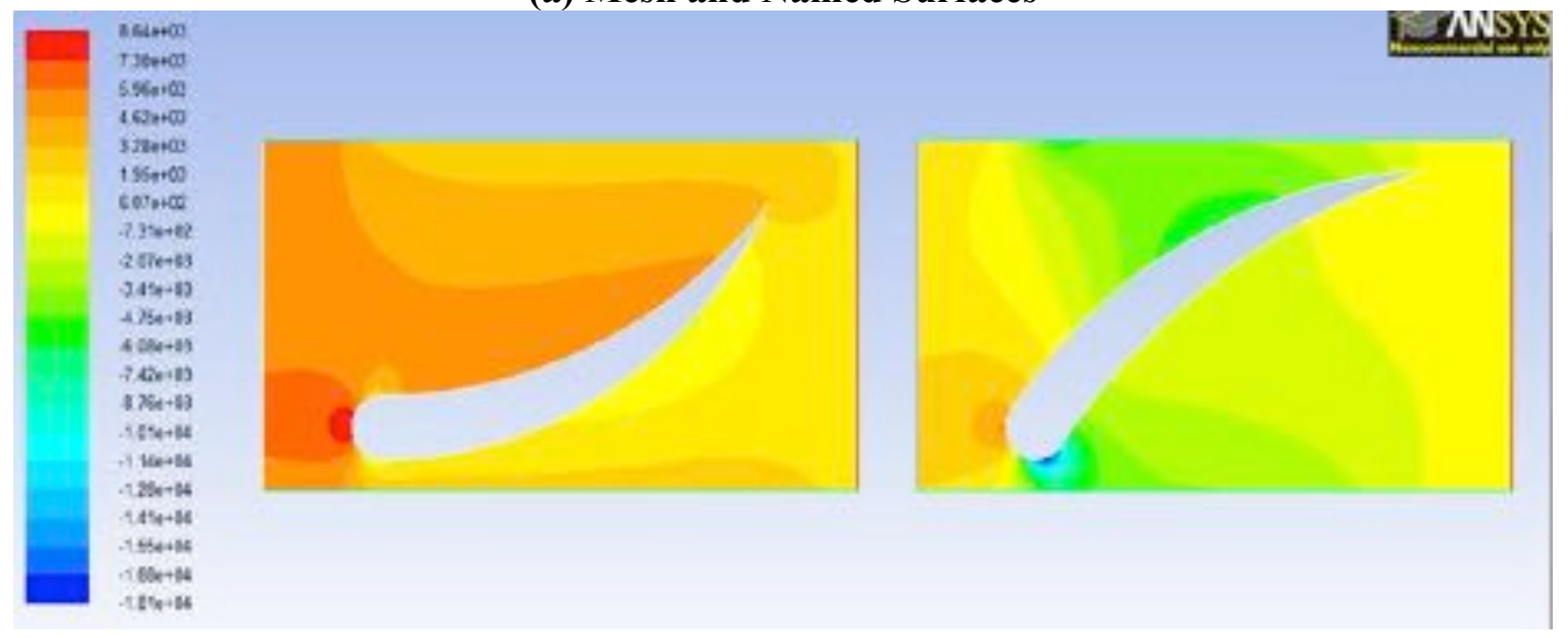

(b) Example Results - Static Pressure Contour Plot

Figure 2: Analysis of a single gas turbine stage; mesh and sample results.

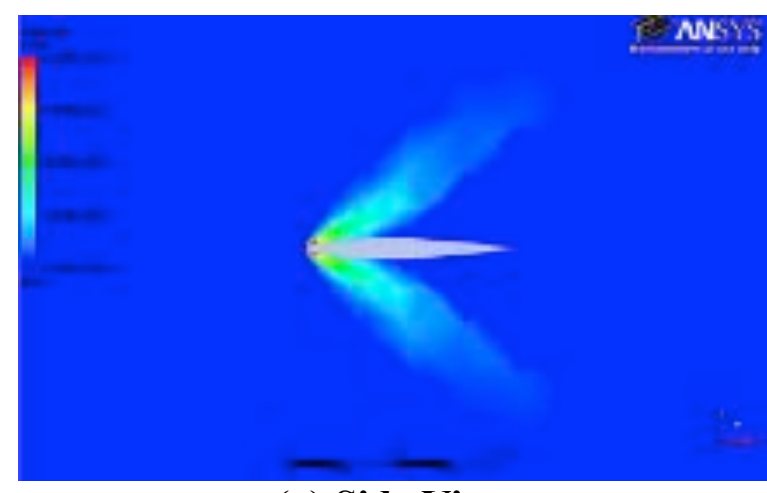

(a) Side View

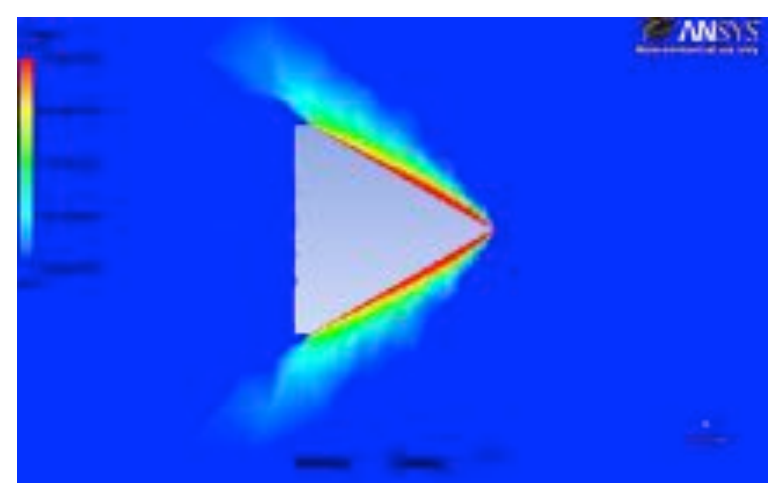

(b) Top View

Figure 3: Pressure contours surrounding a delta wing at Mach 2 and zero angle of attack. 


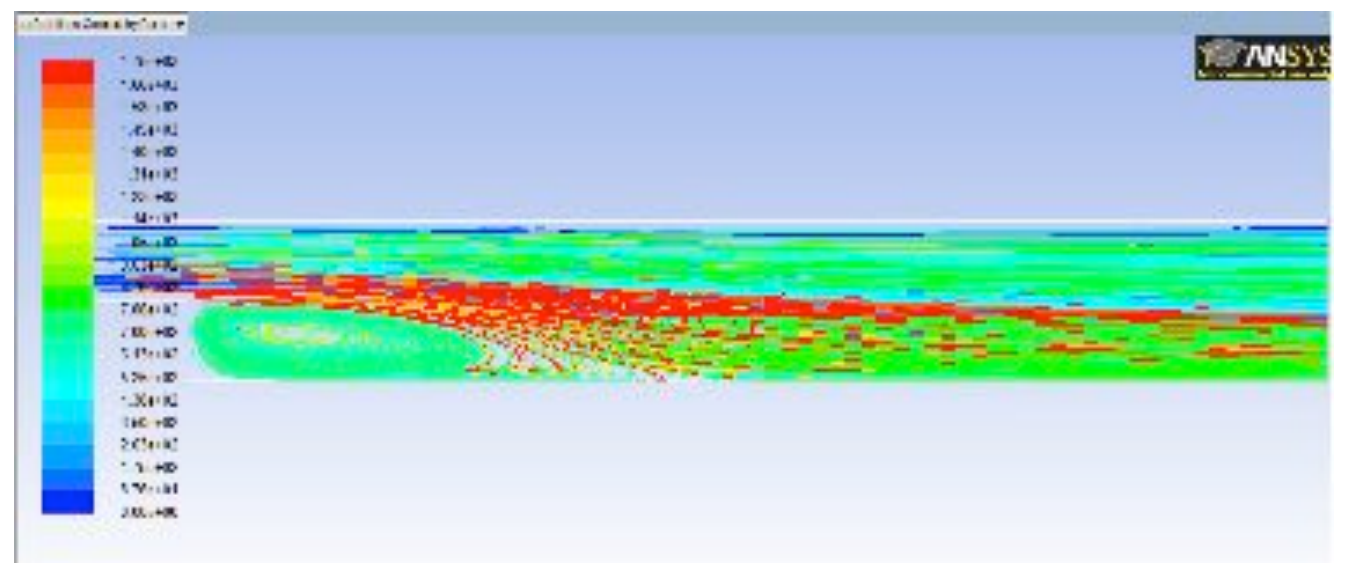

Figure 4: Pathlines for replicated chamber with $12.5 \mathrm{~m} / \mathrm{s}$ inlet velocity.

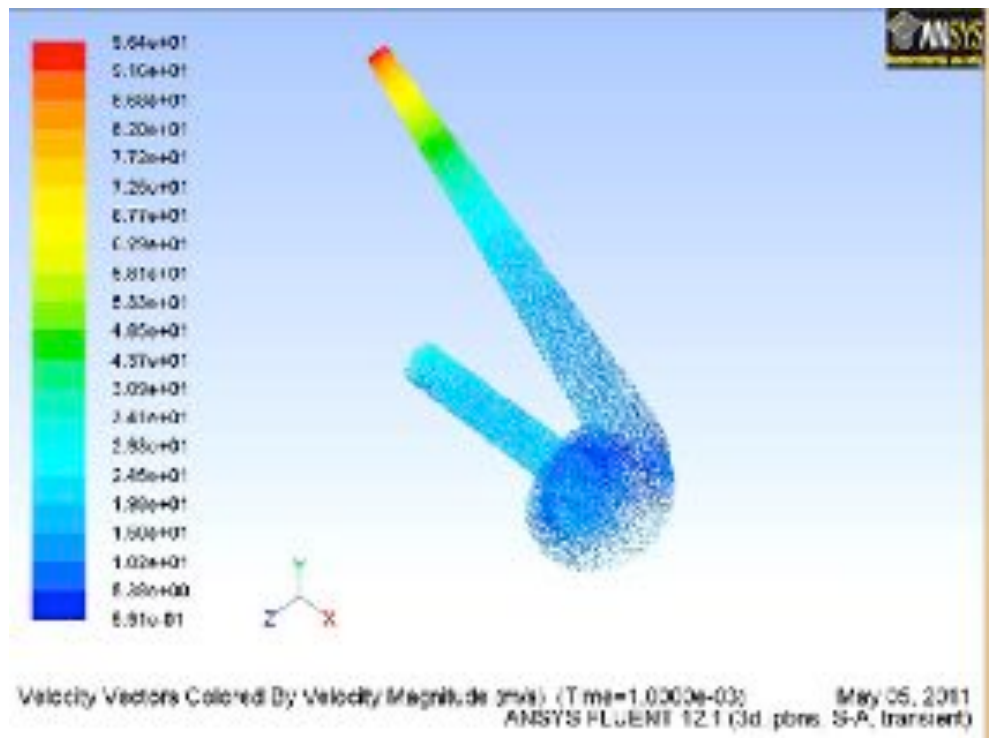

Figure 5: Velocity vectors for FSAE inlet plenum at 0.001 s.

The four examples of student projects that were discussed in this section give some indication of the range of CFD problems considered and the breadth of CFD techniques employed by the students. These examples utilized more advanced techniques that were not addressed in the lecture or laboratory portions of the course. As a result, students had to engage in self-directed learning to find the appropriate techniques for their specific problem and the means to implement those techniques to obtain a solution. This also increased the amount of time the instructor had to spend with each individual student.

\section{Conclusions}

Each student designed and completed a final project over the course of the semester. All of the student-designed projects that were submitted exhibited at least a working knowledge of CFD 
techniques and of the ANSYS software that was used in the course. A majority of the students went beyond the material presented in class and took the initiative to learn the modeling techniques required to solve their specific problem. The wide variety of problems and methods employed resulted in an increased demand on the instructor's time. As a result, the number of students should be limited to a maximum of twenty five if the current course structure is maintained.

\section{Bibliography}

1. ASME V\&V 20-2009, "Standard for Verification and Validation in Computational Fluid Dynamics and Heat Transfer", ASME.

2. Shollenberger, K. A., "Computational Fluid Dynamics (CFD) within Undergraduate Programs", Proceedings of the 2007 ASME International Mechanical Engineering Congress and Exposition, paper no. IMECE2007-43496, Seattle, WA, November, 2007.

3. Tu, J., Yeoh, G. H., and Liu, C., Computational Fluid Dynamics: A Practical Approach, Elsevier Inc., 2008.

4. Patankar, S. V., Numerical Heat Transfer and Fluid Flow, Hemisphere Publishing Corp., 1980.

5. ANSYS Customer Portal, https://www1.ansys.com/customer/default.asp.

6. Cornell University, Fluent Learning Modules, https://confluence.cornell.edu/display/SIMULATION/FLUENT+Learning+Modules.

7. ANSYS Resource Library, http://www.ansys.com/Resource+Library.

\section{DANIEL N. POPE}

Dr. Daniel N. Pope (Dan) is an Associate Professor in the Department of Mechanical and Industrial Engineering at the University of Minnesota Duluth. His education includes a B.S.M.E. (1989), a M.S.M.E. (1993) and a Ph.D. (2001) from the University of Nebraska-Lincoln (UNL), as well as Naval Nuclear Power School and Naval Prototype Training (1990). Dan has held jobs as an officer in the U.S. Navy, a consulting engineer for Black and Veatch's Power Division, and a Research Assistant Professor in the Department of Mechanical Engineering at the University of Nebraska-Lincoln. He has over 15 years of teaching experience in Mechanical Engineering at the undergraduate level and has presented several lectures in graduate level thermal/fluids science courses. His research interests include computational fluid dynamics, the fundamental processes present in fuel droplet vaporization and combustion, biodiesel production and use, and sustainable energy systems. Dan is a member of ASME, SAE, ASEE, and The Combustion Institute. He currently serves as advisor for two UMD student organizations; the ASME student section, and the Formula SAE design team. 